\title{
The Evolutionary Pattern and the Regulation of Stearoyl-CoA Desaturase Genes
}

\author{
Xiaoyun Wu, ${ }^{1,2}$ Xiaoju Zou, ${ }^{3}$ Qing Chang, ${ }^{2}$ Yuru Zhang, ${ }^{2}$ Yunhai Li, ${ }^{2}$ Linqiang Zhang, \\ Jingfei Huang, ${ }^{1}$ and Bin Liang ${ }^{2}$ \\ ${ }^{1}$ State Key Laboratory of Genetic Resources and Evolution, Kunming Institute of Zoology, Chinese Academy of Sciences, \\ Kunming, Yunnan 650223, China \\ ${ }^{2}$ Key Laboratory of Animal Models and Human Disease Mechanisms of the Chinese Academy of Sciences and Yunnan Province, \\ Kunming Institute of Zoology, Kunming, Yunnan 650223, China \\ ${ }^{3}$ Department of Life Science and Biotechnology, Kunming University, Kunming 650214, China
}

Correspondence should be addressed to Bin Liang; liangb@mail.kiz.ac.cn

Received 23 January 2013; Accepted 14 September 2013

Academic Editor: William Piel

Copyright (C) 2013 Xiaoyun Wu et al. This is an open access article distributed under the Creative Commons Attribution License, which permits unrestricted use, distribution, and reproduction in any medium, provided the original work is properly cited.

\begin{abstract}
Stearoyl-CoA desaturase (SCD) is a key enzyme that converts saturated fatty acids (SFAs) to monounsaturated fatty acids (MUFAs) in the biosynthesis of fat. To date, two isoforms of $s c d$ gene ( $s c d 1$ and $s c d 5)$ have been found widely existent in most of the vertebrate animals. However, the evolutionary patterns of both isofoms and the function of $s c d 5$ are poorly understandable. Herein, we aim to characterize the evolutionary pattern of $s c d$ genes and further predict the function differentiation of $s c d$ genes. The sequences of $s c d$ genes were highly conserved among eukaryote. Phylogenetic analysis identified two duplications of $s c d$ gene early in vertebrate evolution. The relative rate ratio test, branch-specific $d N / d S$ ratio tests, and branch-site $d N / d S$ ratio tests all suggested that the $s c d$ genes were evolved at a similar rate. The evolution of $s c d$ genes among eukaryote was under strictly purifying selection though several sites in $s c d 1$ and $s c d 5$ were undergone a relaxed selection pressure. The variable binding sites by transcriptional factors at the $5^{\prime}$-UTR and by miRNAs at $3^{\prime}$-UTR of $s c d$ genes suggested that the regulators of $s c d 5$ may be different from that of $s c d 1$. This study promotes our understanding of the evolutionary patterns and function of SCD genes in eukaryote.
\end{abstract}

\section{Introduction}

Stearoyl-CoA desaturase (SCD) is an intrinsic membrane protein that binds to the endoplasmic reticulum (ER), composed of four transmembrane domains [1-3]. SCD is the ratelimiting enzyme that introduces the first cis-double bond at the delta-9 position of saturated fatty acids (SFAs) to thereby generate monounsaturated fatty acids (MUFAs) [4], which are major substrates for biosynthesis of polyunsaturated fatty acids (PUFAs) and complex lipids such as triglycerides, phospholipids, cholesterol esters, and wax esters being as energy storage, components of biological membrane, and signaling molecules. The ratio of unsaturated fatty acids to saturated fatty acids plays a vital role in cell signaling and membrane fluidity, in which imbalance of this ratio is often associated with diseases like diabetes, cardiovascular diseases, fatty liver, cancers and stresses resistance, and so forth [5].

The $s c d$ genes are universally present in living organisms. The number of $s c d$ genes varies from one to five, which are generally called $s c d 1, s c d 2, s c d 3, s c d 4$, and $s c d 5$ in different organisms $[4,6]$, but with other distinct names in invertebrates such as fat-5, fat-6, and fat-7 in Caenorhabditis elegans [7-9] and ole1 in Saccharomyces cerevisiae [10]. The yeast genome contains only ole-1 gene encoded SCD, and ole-1 mutant requires unsaturated fatty acids for growth [10]. The desaturase of $C$. elegans FAT-5, FAT-6, and FAT7 displays substrate preferences, in which both FAT- 6 and FAT-7 mainly desaturate stearic acid (18:0) and have less activity on palmitic acid $(16: 0)$. On the contrary, FAT-5 desaturates palmitic acid $(16: 0)$ but has nearly undetectable activity on stearic acid $(18: 0)$ [7]. The evolutionary history 
revealed that the $s c d$ genes in vertebrates could be distinctly classified into $s c d 5$ type $[3,6,11]$ and $s c d 1$ type including its homologs $s c d 2, s c d 3$, and $s c d 4[6,12]$. The divergence of $s c d 1$ and $s c d 5$ genes occurred early in vertebrate evolution due to the whole genome duplication (2R) [6]. However, the scd genes may have distinct fates after gene duplication event. It is unknown whether one scd evolved faster and acquired new function more rapidly than the other, and whether the selective patterns on both $s c d$ genes were similarly changed following the duplication.

Interestingly, though the enzymes of $s c d$ genes display similar delta-9 desaturation activity [4], the expression pattern of $s c d 1$ and $s c d 5$ is variable that $s c d 1$ is ubiquitous, but $s c d 5$ is mainly in the brain and pancreas even in different species $[3,6,11]$, implying that the regulation of $s c d 1$ and $s c d 5$ expression and biological function may be distinct. The promoter region of $s c d 1$ contains many consensus binding sites for numerous transcription factors, for example, SREBP1, LXR, PPAR $\alpha$, C/EBP- $\alpha$, NF-1, NF-Y, and Sp1 [13]. However, it is unclear whether scd5 contains similar or completely different consensus binding sites with $s c d 1$. Meanwhile, it is completely unknown that the $3^{\prime}$-UTR of $s c d 1$ and $s c d 5$ that may also contain similar or different target sites of microRNAs regulating their expression.

Therefore, to address the above questions, we compared the sequence characteristics of scd paralogs and then reconstructed the phylogenetic trees of scd genes in eukaryote species to determine the evolutionary history of $s c d$ genes. We used the relative rate ratio test, branch-specific $d N / d S$ ratio tests, and branch-site $d N / d S$ ratio tests to analyze the evolutionary forces after gene duplication. Furthermore, we characterized the binding sites by transcript factors in the $5^{\prime}$ UTR and the target sites by microRNAs in the $3^{\prime}$-UTR of $s c d 1$ and $s c d 5$ genes to investigate the regulation mechanisms of both $s c d$ genes.

\section{Material and Methods}

2.1. SCD Homologs BLAST, Sequence Alignment, and Phylogenetic Analysis. SCD homologs were retrieved by key word "Stearoyl-CoA desaturase" from NCBI GenBank (http:// www.ncbi.nlm.nih.gov/genbank/) and Ensemble genome database (http://asia.ensembl.org/index.html). In addition, the sequences of human SCD proteins were used to blast available genomes from NCBI GenBank and Ensemble database. Eventually, $73 \mathrm{scd}$ nucleotide sequences from 39 representative eukaryote species were retrieved (see Table S1 in the Supplementart Material available online at http://dx.doi.org/10.1155/2013/856521). Sequence alignment of $73 \mathrm{scd}$ nucleotides was performed with MegAlign implemented in DNAStar 6.0 software package (DNASTAR, Madison, USA) and then was confirmed visually by BioEdit 7.0.9 [14]. The ambiguous regions of alignment were discarded and eventually 720 nucleotide bases were obtained.

Phylogenetic tree was reconstructed based on the full alignment of 73 sequences by using Maximum Likelihood (ML) analysis in PHYML [15] and approximately Maximum Likelihood (ML) analysis in FastTree 2.1.3 [16]. The yeast $s c d$ ortholog, ole1, was used as the outgroup to root the tree. For ML analysis, supports for nodes among branches were evaluated using nonparametric bootstrapping [17] with 1000 bootstrap replications. For FastTree 2 analysis, a heuristics search strategy was employed with an estimated rate of evolution for each site (the "CAT" approximation), minimumevolution subtree-pruning regrafting (SPRs), and maximumlikelihood nearest-neighbor interchanges (NNIs). The local support values were provided based on the ShimodairaHasegawa (SH) test $[18,19]$.

To evaluate the evolutionary conservation of the SCD1 and SCD5, the amino acid sequences of SCD1 and SCD5 of 11 model organisms including human, rhesus monkey, mouse, rat, tree shrew, zebrafish, Drosophila melanogaster, and $C$. elegans were retrieved and then aligned using Muscle (http://www.ebi.ac.uk/Tools/msa/muscle/), followed by manual adjustment with BioEdit 7.0.9 [14]. Additionally, a Neighbouring-Joining (NJ) tree was reconstructed with the amino acid sequences of SCDs from human, rhesus monkey, mouse, rat, tree shrew, and C. elegans by MEGA 4.0 [20] using amino acid p-distance model. Support for nodes among branches was evaluated using nonparametric bootstrapping [17] with 1000 bootstrap replications.

2.2. Regulation Prediction in $3^{\prime}$-UTR and $5^{\prime}$-UTR of scd Genes. Searching for the transcription factor-binding sites (TFBS) in the $5^{\prime}$-UTR of $s c d$ genes was carried out based on the positive effectors of transcription in the promoter region of $s c d 1$ from human, mouse, and chicken [13]. The length of $5^{\prime}$-UTR for this analysis was about $2500 \mathrm{bp}$ upstream of the translational start sites of $s c d 5$ gene. The TFBSs were estimated by Match 1.0 with the TRANSFAC database v. 6.0 and Promo with TRANSFAC database v. 8.3 [21, 22]. The cutoff parameters were set as 0.75 for the core similarity and 0.85 for matrix similarity in Match 1.0 analysis. In Promo analysis, the species of factor and site were only constrained to animals. MultiSearchSite was used to search for binding sites sharing $15 \%$ maximum matrix dissimilarity rate in the promoter sequences of human, rhesus monkey, tree shrew, and chicken.

The microRNA targets sites in the $3^{\prime}$-UTR region of scd genes were predicted by using TargetScan release 6.2 (http://www.targetscan.org/). The lengths of the $3^{\prime}$-UTR region of $s c d 1$ and $s c d 5$ genes were about $4000 \mathrm{bp}$ and $1790 \mathrm{bp}$, respectively. Only the broadly conserved sites for miRNA families among vertebrates were considered in this study. The predicted miRNAs were then introduced to the miR2Disease Base (http://www.mir2disease.org/) to establish the relationship between miRNAs and human diseases.

2.3. Relative Rate Test. The substitution rates of the $s c d$ genes were compared among different paralogs inferred from the phylogenetic tree using the relative rate test implemented in RRTree [23]. Three phylogroups were defined as vertebrate $s c d 1$, vertebrate $s c d 5$, and invertebrate $s c d$ gene. The yeast ole1 gene was used as outgroup. 
2.4. Selective Pattern Analysis. The ratio of synonymous substitution to nonsynonymous substitution $(\omega=d N / d S)$ is a good indicator to estimate the evolutionary selective pressure of protein-coding regions. The ratio of $\omega=1,<1$, and $>1$ indicates a neutral selection, a purifying selection, and positive selection, respectively. The $\omega$ ratios between pairwise sequences were estimated following the method of Yang and Nielsen [24].

The codon-substitution models were implemented using CODEML in PAML package [25]. All models fixed the transition/transversion rate and codon usage biases $(\mathrm{F} 3 \times 4)$. To determine the evolutionary selective patterns of two $s c d$ genes, the branch-specific model was applied to the data, which assumed that the foreground clade had different ratios from the background clade [26]. In model B, scd1 and $s c d 5$ genes were set as the foreground clade. In model C, $s c d 1$, $s c d 5$, and the invertebrate SCD homologs were set as three clades. In addition, we also determined the sites evolving under positive selection in a specific clade with the branchsite model that allows variation in $\omega$ across individual codons on a specific lineage [27]. We applied the modified branch-site model A (test 1 and test 2) [27], which permits variation of the $\omega$ ratio both among sites and lineages. The likelihood ratio tests (LRTs) were constructed to compare the fit to the data of two nested models. The significant difference between two models was evaluated by calculating twice the log-likelihood difference, and followed an $\chi^{2}$ distribution with the number degree of freedom equal to the difference in the number of free parameters.

\section{Results}

3.1. The Sequence Characteristics of SCD Orthologs. In human, the size of $s c d 1$ gene is about $17 \mathrm{~kb}$ and $170 \mathrm{~kb}$ for $s c d 5$ gene. Though the remarkably different sizes of two $s c d$ genes, the full lengths of both $s c d$ encoded proteins are very close that SCD1 has 359 aa and SCD5 330 aa (Figure 1). To determine the conservation of SCD orthologs, we first investigated the sequence characteristics of SCD proteins. Comparison of the SCD amino acid sequences from several animal organisms revealed that the three histidine motifs HRLWSH, HRAHH, and HNYHH that exist in human SCD are also highly conserved in all alignments (Figure 1). But, the three histidine motifs also display minor changes in some organisms. For example, HRLWAH exists in $C$. elegans FAT-5 and Drospholia SCD genes; HNFHH in C. elegans FAT-6 and FAT-7 (Figure 1). The four transmembrane hydrophobic domains marked underline are also conserved in all alignments (Figure 1). Then, we investigated the sizes and order of exons of $s c d$ genes in several representative eukaryote organisms (Figure 2). Most of the scdl genes (e.g., chicken, human, etc.) are consisted of 6 exons. However, some vertebrate $s c d 1$ genes only have 5 exons, like platypus and zebrafish. All of the $s c d 5$ genes are consisted of 5 exons. Very interestingly, except the exon 1, the sizes and order of other exons (exon 2 (131), exon 3 (206), exon 4 (233), and exon 5 (191)) of $s c d 5$ genes were not only separately equal but also very similar to the sizes and order of the third to sixth exons of $s c d 1$ genes (exon 3 (131), exon 4 (206), exon 5 (233) and exon $6(200)$ ) in eukaryote organisms (Figures $2(a)$ and 2(b)).

3.2. Phylogenetic Inference of scd Gene Lineages. The phylogenetic tree of $s c d$ genes based on the 73 nucleotide sequences from 39 species is shown in Figure 3(a) (TreeBASE Accession URLhttp://purl.org/phylo/treebase/phylows/study/ TB2:S14739). The scd orthologs of invertebrate species are placed at the base of the tree using $s c d$ ortholog yeast ole1 as outgroup. The C. elegans fat-5, fat- 6 , and fat-7 are placed at the most basal position of the tree. In addition, the scdla, scdlb, and scdlc from Ciona savignyi and amphioxus Branchiostoma floridae are just located out of the vertebrate lineages. Intriguingly, the $s c d$ genes in vertebrates are split into two lineages with strong support (support value = 99\%) according to the scd gene classification, suggesting that independent duplication events occurred in vertebrates after separation from invertebrates during evolution. In teleost fish, two $s c d 1$ paralogs were also diverged into two independent clades with high support, but the $s c d 5$ gene was lost. This evolutionary pattern might suggest that the teleost fish $s c d$ experienced an ancient gene duplication event [12] or the genome duplication [6].

3.3. Evolutionary Rates and Selective Pattern in scd Genes. To determine whether the paralogs of $s c d$ evolve at the similar rates, the relative rate analysis was performed among $s c d$ gene and in which the invertebrate $s c d$ genes, vertebrate $s c d 1$ and $s c d 5$ genes were separated into 3 groups using the yeast ole1 as outgroup. The analysis revealed that the $s c d$ genes were evolved at the similar evolutionary rate $(P<0.05)$.

To address the selective constraint pattern within $s c d$ genes, the ratios of nonsynonymous $(d n)$ to synonymous (ds) were estimated between two sequences. The analysis suggested that nearly almost pairwise comparisons of $s c d$ genes had a $\omega<1$, indicating a strong purifying selection. Intriguingly, the pairwise comparisons among $s c d 1$ genes of human, gorilla, and chimpanzee had a $\omega=\infty$, which might result from that the nonsynonymous substitution occurred while the synonymous substitution did not in $s c d 1$ sequences probably because of the very close relationships among these three species.

The selective pattern of $s c d$ genes was further performed using the condon-based maximum likelihood analysis (Table 1). In this analysis, the yeast ole1 was excluded. The estimated one ratio of $\omega_{0}(0.08684)$ over all sites and branches from the $s c d$ genes was substantially smaller than 1 , suggesting a strong purifying selection (Table 1). In the branch-specific models, Model B assumes $s c d 1$ gene and $s c d 5$ gene as the foreground clades, respectively. In this model the estimated $\omega$ value was 0.09207 for $s c d 1$ gene and 0.07951 for the background clades. The estimated $\omega$ value was 0.06146 for scd5 gene and 0.09735 for the background clades. The LRT test suggested that the two-ratio model was not fit for the data better than the one-ratio model for $s c d l$ gene $(P>0.05)$ but fit better for $s c d 5$ gene $(P<0.001)$. Under Model $C, \omega$ estimates for $s c d 1, s c d 5$, and invertebrate $s c d$ gene were $0.06140,0.09198$, and 0.11788 , respectively. The LRT test indicated that Model C 


\begin{tabular}{|c|c|}
\hline . elegans FAT5 & ----QIKVDAI ISKQFLAAD-----------LNEIRQMQEE----SKKQV \\
\hline C. elegans FAT6 & --TVKTRSNIAKKIEKDGGPETQYLAVD--- \\
\hline C. elegans FAT7 & --TVKTRASIAKKIEKD-GLDSQYLFMD-- \\
\hline uit fly SCD & GAQSISDSLIAAASAAADAGQSPTKLQEDSTGV \\
\hline ebrafish SCD1a & LQPQLEAM- \\
\hline Zebrafish SCD1b & --- ADVTTTT --------- . \\
\hline tropicalis SCD1 & M-------TFRGSQTVSTVMESPSIIQDEIGADRVMT- \\
\hline $\mathrm{D} 1$ & MPAHMLQE-I \\
\hline Tree shrew SCD1 & PPSRVLQNGGGKLEKTSLCFDED \\
\hline honkey SCD1 & \\
\hline 1 & MPAH \\
\hline ree shrew SCD5 & $\mathrm{M}^{--------- \text {PGLAADAGKVPFCDAKEEIRAG }^{--}-\mathrm{L}^{-}}$ \\
\hline hesus monkey SC & $\mathrm{M}^{--}$ \\
\hline Iuman SCD5 & - PGPATDAGKIPFCDAKEEIRAG ${ }^{---} \mathrm{L}$ \\
\hline
\end{tabular}

C. elegans FAT5

C. elegans FAT6

C. elegans FAT7

Fruit fly SCD

Zebrafish SCD1a

Zebrafish SCD1b

Xenopus tropicalis SCD1

Mouse SCD1

Tree shrew SCD1

Rhesus monkey SCD1

Human SCD1

Tree shrew SCD5

Rhesus monkey SCD5

Human SCD5

IKME-IVWKNVALFVALHIGALVGLYQLVFQAKWATVGWVFLLHTLGSMGVTGGAHRLWAHRAYKATLSW YKVE-IVWRNVALFAALHFAAAIGLYQLIFEAKWQTVIFTFLLYVFGGFGITAGAHRLWSHKSYKATTPM YKME-IVWRNVALFAALHVAAAIGLYELVFHAKWQTAVFSFALYVFSGFGITAGAHRLWSHKSYKATTPM RRLK-LVWRNI IAFGYLHLAALYGAYLVVTSAKWQTCILAYFLYVISGLGITAGAHRLWAHRSYKAKWPL PPMK-IVWRNVILMSLLHIAAVYGLF-LIPSAHPLTLLWAFACFVYGGLGITAGVHRLWSHRSYKATLPL PPVQ-IVWRNV ILMTLLHLGALYGMT-ILPFVSSLTLIWTGVCFMVSALGITAGAHRLWSHRSYRASLPL PPIK-LVWRNVILMALLHFGAFYGLF-MIPAAKPITLAWAILCFMLSALGVTAGAHRLWSHRSYKAKLPI PKLE-YVWRNI ILMVLLHLGGLYGII-LVPSCKLYTCLFGIFYYMTSALGITAGAHRLWSHRTYKARLPL PKLE-YVWRNI ILMSLLHLGALYGIV-LFPTSKFYTWLWVLFYYLVSALGITAGAHRLWSHRTYKARLPL PKVE-YVWRNI ILMSLLHLGALYGIT-LIPTCKLYTCLWGLFYYVVSALGITAGAHRLWSHRSYKARLPL PKVE-YVWRNIILMSLLHLGALYGIT-LIPTCKFYTWLWGVFYYFVSALGITAGAHRLWSHRSYKARLPL GRRQNIVWRNVVLMSLLHLGAVYSLV-LIPKAKPLTLLWAYFCFLLTALGVTAGAHRLWSHRSYKAKLPL GQRQNIVWRNVVLMSLLHLGAVYSLV-LIPKAKPLTLLWAYFCFLLAALGVTAGAHRLWSHRSYKAKLPL GQRQNIVWRNVVLMSLLHLGAVYSLV-LIPKAKPLTLLWAYFCFLLAALGVTAGAHRLWSHRSYRAKLPL

C. elegans FAT5

C. elegans FAT6

C. elegans FAT7

Fruit fly SCD

Zebrafish SCD1a

Zebrafish SCD1b

Xenopus tropicalis SCD1

Mouse SCD1

Tree shrew SCD1

Rhesus monkey SCD1

Human SCD1

Tree shrew SCD5

RVFLMLINSIAFQNDI IDWARDHRCHHKWTDTDADPHSTNRGMFFAHMGWLLVKKHDQLKIQGGKLDLSD RIFLMILNNIALQNDVIEWARDHRCHHKWTDTDADPHNTTRGFFFAHMGWLLVRKHPQVKEQGAKLDMSD RIFLMLLNNIALQNDI IEWARDHRCHHKWTDTDADPHNTTRGFFFTHMGWLLVRKHPQVKEHGGKLDLSD RVILVIFNTIAFQDAAYHWARDHRVHHKYSETDADPHNATRGFFFSHVGWLLCKKHPEVKAKGKGVDLSD RIFLAIGNSMAFQNDIYEWSRDHRVHHKYSETDADPHNSNRGFFFSHVGWLLVRKHPEVIERGRKLELTD RIFLAVANSMAFQNDIYEWARDHRVHHKFSETDADPHNARRGFFFAHIGWLLVRKHPEVIDKGRKLTFED RIFLAVVNSMAFQNDIYEWARDHRVHHKYSETDADPHNAVRGFFFSHIGWLLMRKHPDVIEKGKKLDLSD RIFLIIANTMAFQNDVYEWARDHRAHHKFSETHADPHNSRRGFFFSHVGWLLVRKHPAVKEKGGKLDMSD RLFLIIANTMAFQNDVYEWARDHRVHHKFSETHADPHNARRGFFFSHVGWLLVRKHPAVKEKGALLDLSD RLFLIIANTMAFQNDVYEWARDHRAHHKFSETHADPHNSRRGFFFSHVGWLLVRKHPAVKEKGATLDLSD RLFLIIANTMAFQNDVYEWARDHRAHHKFSETHADPHNSRRGFFFSHVGWLLVRKHPAVKEKGSTLDLSD RIFLAAANSMAFQNDIFEWCRDHRVHHKYSETDADPHNARRGFFFSHIGWLFVRKHRDVIEKGRKLDFTD RIFLAVANSMAFQNDIFEWSRDHRAHHKYSETDADPHNARRGFFFSHIGWLFVRKHPDVIEKGRKLDVTD Rhesus monkey SCD5 Human SCD5 RIFLAVANSMAFQNDIFEWSRDHRAHHKYSETDADPHNARRGFFFSHIGWLFVRKHRDVIEKGRKLDVTD

C. elegans FAT5 C. elegans FAT6 C. elegans FAT7 Fruit fly SCD Zebrafish SCD1a Zebrafish SCD1b Xenopus tropicalis SCD1 Mouse SCD1 Tree shrew SCD1 Rhesus monkey SCD1 Human SCD1 Tree shrew SCD5 Rhesus monkey SCD5 Human SCD5

LYEDPVLMFQRKNYLPLVGIFCFALPTFIPVVLWGESAFIAFYTAALFRYCFTLHATWCINSVSHWVGWQ LLSDPVLVFQRKHYFPLV ILCCFILPTI IPVYFWKETAF IAFYTAGTFRYCFTLHATWC INSAAHYFGWK LFSDPVLVFQRKHYFPLVILFCFILPTI IPVYFWKETAF IAFYVAGTFRYCFTLHATWCINSAAHYFGWK LRADPILMFQKKYYMILMPIACFI IPTVVPMYAWGESFMNAWFVATMFRWCFILNVTWLVNSAAHKFGGR LKADKVVMFQRRFYKLSVVLMCFVVPTVVPCYMWGESLWIAYFIPTLLRYALGLNSTWLVNSAAHMWGNR LKADSVVMFQRRHYKLSVVVMCFLIPTLVPWFFWEESLWTAYLVPCLLRYAVVLNATWLVNSAAHMWGMR LKADKVVMFQRRNYKLSILVMCFILPTVIPWYFWDESFSVAFYVPCLLRYALVLNATWLVNSAAHMYGNR LKAEKLVMFQRRYYKPGLLLMCFILPTLVPWYCWGETFVNSLFVSTFLRYTLVLNATWLVNSAAHLYGYR LRAEKLVMFQRRYYVPGVLLMCFILPTLVPWCLWGETFMHSLYVATLLRYATVLNATWLVNSAAHLYGYR LEAEKLVMFQRRYYKPGLLLMCFILPTLVPWCFWGETFQHSVFVATFLRYAIVLNVTWLVNSAAHLFGYR LEAEKLVMFQRRYYKPGLLMMCFILPTLVPWYFWGETFQNSVFVATFLRYAVVLNATWLVNSAAHLFGYR LLADPVVRFQRKYYK ITVVLMCFAVPTLVPWYIWGESLWNSYFLAS ILRYTISLNVTWLVNSAAHMYGNR LLADPVVRIQRKYYKISVVLMCFAVPTLVPWYIWGESLWNSYFLASILRYTISLNVAWLVNSAAHMYGNR LLADPVVRIQRKYYKISVVLMCFVVPTLVPWYIWGESLWNSYFLASILRYTISLNISWLVNSAAHMYGNR

C. elegans FAT5 C. elegans FAT6 C. elegans FAT7 Fruit fly SCD Zebrafish SCD1a Zebrafish SCD1b Xenopus tropicalis SCD1 Mouse SCD1 Tree shrew SCD1 Rhesus monkey SCD1 Human SCD1 Tree shrew SCD5 Rhesus monkey SCD5 Human SCD5

PYDHQASSVDNLWTSIAAVGEGGHNYHHTFPQDYRTSEHA-EFLNWTRVLIDFGASIGMVYDRKTTPEEV PYDSSITPVENVFTTIAAVGEGGHNFHHTFPQDYRTSEYS-LKYNWTRVLIDTAAALGLVYDRKTACDEI PYDTSVSAVENVFTTVVAVGEGGHNFHHTFPQDYRASEYS-LIYNWTRVLIDTAAVLGLVYDRKTIADEF PYDKFINPSENISVAILAFGEGWHNYHHVFPWDYKTAEFGKYSLNFTTAFIDFFAKIGWAYDLKTVSTDI PYDGNIGPRENRFVTFSAIGEGYHNYHHTFPYDYSTSEYG-WKLNLTT IFVDTMCFLGLASNRKRVSKEL PYDHNINPRENKFVAFSAIGEGFHNYHHTFPHDYATSEFG-SRLNVTKAFIDLMCFLGLANDCRRVTHET PYDQTINPRENPLVAIGAIGEGFHNYHHTFPFDYSTSEFG-LKFNITTGFIDLMCLLGLANDCKRVSKET PYDKNIQSRENILVSLGAVGEGFHNYHHTFPFDYSASEYR-WHINFTTFFIDCMAALGLAYDRKKVSKAT PYDKTINPRENILVSLGAVGEGFHNYHHTFPYDYSASEYR-WHINLTTFFIDCMAALGLAYDRKKVSKAA PYDKNISPRENILVSLGAVGEGFHNYHHSFPYDYSASEYR-WHINFTTFFIDCMA-

PYDKNISPRENILVSLGAVGEGFHNYHHSFPYDYSASEYR-WHINFTTFFIDCMAALGLAYDRKKVSKAA PYNKHISPRQNPLVTLGAIGEGFHNYHHTFPFDYSASEFG-LNFNPTTWF IDFMCWLGLATDRKRAPKPM PYDKHISPRQNPLVALGAIGEGFHNYHHTFPFDYSASEFG-LNFNPTTWFIDLMCWLGLATDRKRATKPM PYDKHISPRQNPLVALGAIGEGFHNYHHTFPFDYSASEFG-LNFNPTTWFIDFMCWLGLATDRKRATKPM

(a)

FIgure 1: Continued. 


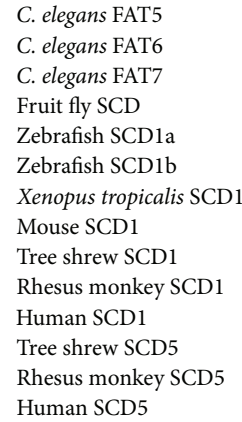

\begin{tabular}{|c|}
\hline 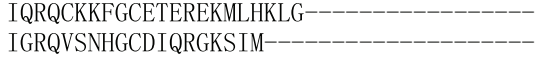 \\
\hline ISRQVANHGSEESRKKSIM \\
\hline IKKRVKRTGDGTHATWGWGDVDQPKEEIEDAVITHKKSE \\
\hline 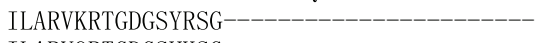 \\
\hline ILARVQRTGDGSHKSG- \\
\hline IMARKKRTGDGSHRSG- \\
\hline VLARIKRTGDGSHKSS- \\
\hline VLARIKRTGDGTYKSG ${ }^{-}$ \\
\hline ILARIKRTGDGNYKSG \\
\hline $\begin{array}{l}\text { IEAQKARTGDGSA }{ }^{---} \\
\text {IEARKARTGDSSA--- }^{---}\end{array}$ \\
\hline $\begin{array}{l}\text { IEARKARIGDSSA---------- } \\
\text { IEARKARTGDSSA--------- }\end{array}$ \\
\hline
\end{tabular}

(b)

FIGURE 1: Alignment of inferred SCD protein sequences from 8 model animals. The three histidine motifs are in bold, and the four transmembrane hydrophobic domains were marked underline.

was significantly better fit for the data than did the one ratio model $(\mathrm{M} 0)(P<0.001)$.

In addition, we determined the amino acid sites under positive selection at SCD1 and SCD5 clades on the phylogeny using the branch-site model. In this model, the SCD1 and SCD5 clades were assumed as the foreground clades, respectively. As seen in Table 1 , the results of test 1 analysis designated several amino acid sites under the relaxed selection $(P<0.001)$ in both the $s c d 1$ and $s c d 5$ genes. However, none of the LRT test for $s c d$ genes was significant in test 2 analysis, indicating that the null hypothesis of the test 2 could not be rejected in both of the scd genes, and none of the two $s c d$ genes was underrelaxed selective constraint or under positive selection. Thus, we did not find any evidence for positive selection in both of the $s c d$ genes under these analyses.

3.4. The Regulation Analysis of scd Genes. Numerous transcription factors, for example, SREBP1, LXR, PPAR $\alpha$, C/EBP$\alpha, \mathrm{NF}-1, \mathrm{NF}-\mathrm{Y}$, and Sp1, have been revealed to bind to the $s c d 1$ promotor region [13]. The consensus binding sites for the SREBP1, PPAR- $\alpha$, C/EBP- $\alpha$, NF-1, and NF-Y were known to mediate the insulin response, whereas the binding sites for Sp1 and AP1 were known to be the leptin response element. To determine whether these transcription factors also bind to $s c d 5$ promotor region, the transcription binding site prediction was performed by using TRANSFAC and Promo. C/EBP- $\alpha$, AP1, SP1, NF-1, NF-Y, and SREBP1 were detected at the promoter region of $s c d 5$ gene of four species (Table 2). But SREBP1 was not detected in the promoter region of $s c d 5$ gene in other mammals (results not shown). Because SREBPs are weak transcriptional activators on their own, they interact with their target promoters in cooperation with additional regulators, most commonly including one or both of the transcription factors NFY and SP1 [28-30], and their binding sites were possessed a high degree of overlap [31]. We also detected the binding sites of NFY and SP1 near the binding site of SREBP1 in human. In this analysis, we detected the binding site of PPAR $\alpha$ by Promo, but not by TRANSFAC. However, the binding site of PPAR $\alpha$ detected in $s c d 5$ gene was different from that of in $s c d 1$ gene (Table 2).
Though most of the transcription factor binding sites in $s c d 1$ gene could be detected in $s c d 5$ gene, the regulation of these transcription factors on $s c d 5$ gene still needs further experimental verification.

In order to compare the microRNAs regulation on $s c d$ genes, we predicted the microRNA target sites at the $3^{\prime}$ UTR region of $s c d 1$ and $s c d 5$ genes using TargetScan. The lengths of $3^{\prime}$-UTR region of $s c d 1$ and $s c d 5$ gene were about $4000 \mathrm{bp}$ and $1790 \mathrm{bp}$, respectively (Figure 4). Within the $3^{\prime}$ UTR region of $s c d 1$ gene, 8 conserved sites of microRNA families were predicted among vertebrates and 5 conserved sites were predicted among mammals (Figure 4(a)). Among these 13 microRNA families, almost all of them were closely associated with the cancers, for example, the miR-128, Let 7, miR-206, and miR-124a linked to breast cancer [32-35], hepatocellular carcinoma [36-38], and pancreatic cancer [39, 40]. In addition, plenty of evidence has described that the $s c d 1$ acted as a potential target to prevent or treat metabolic syndrome. Among these microRNA families, several microRNAs were associated with the nonalcoholic fatty liver disease (NAFLD), type 2 diabetes, and diabetic nephropathy; for example, miR-429 and Let 7cde were closely related to NAFLD [41, 42]; miR-181a related to diabetes [43]; miR216 a related to diabetic nephropathy [44]. At the $3^{\prime}$-UTR region of $s c d 5$ gene, 5 conserved sites of microRNA families were predicted among vertebrates and 2 conserved sites were predicted among mammals (Figure 4(b)). All of these microRNA families were closely associated with cancers. scd5 gene was mainly expressed in brain and pancreas. Several microRNAs were associated with the neurological disorder and pancreatic cancers. miR-106a was associated with autism [45], miR-17 with glioma [46], miR-20b with schizophrenia [47]. miR-205, miR-221, miR-222, miR-17-5p, and miR-20a were associated with pancreatic cancers [39, 48-50]. Only 2 microRNAs, miR-200ab and miR-17, were linked to NAFLD $[41,42]$.

\section{Discussion}

The phylogenetic trees show that homologs of $s c d$ gene from invertebrates were all placed at the basal position of the tree, 


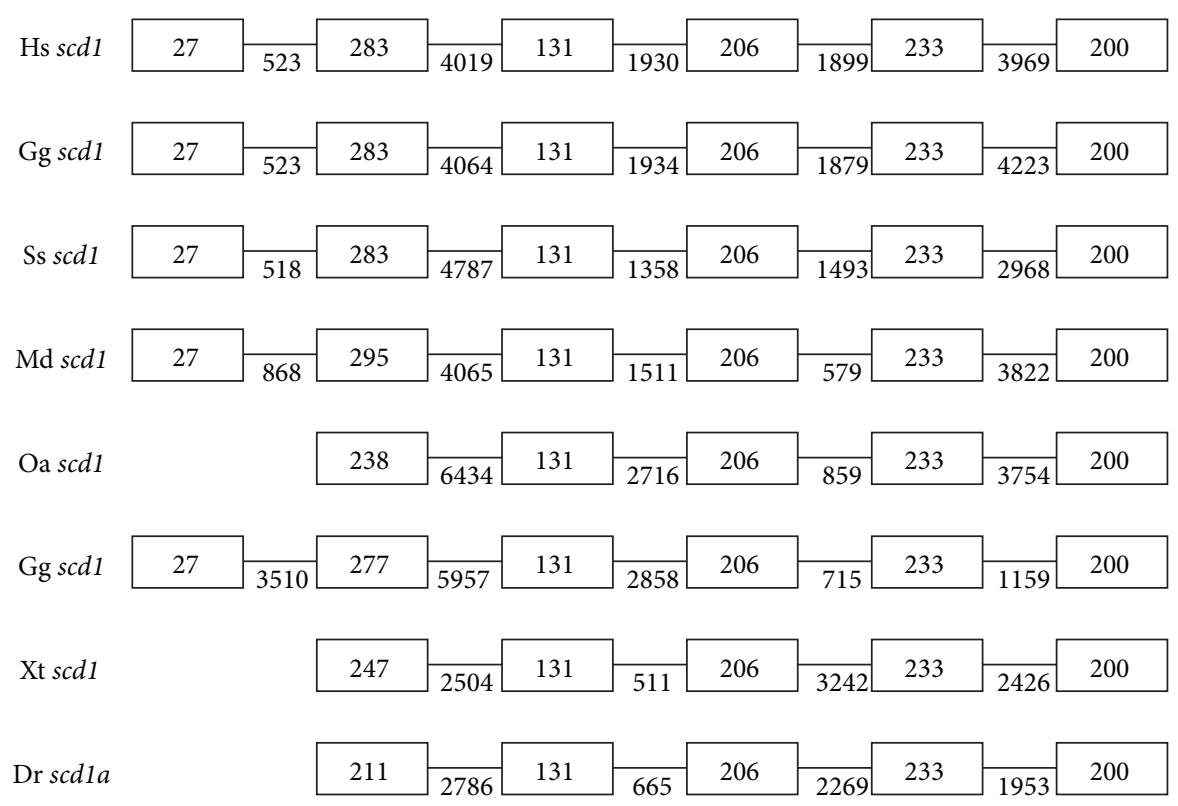

(a)

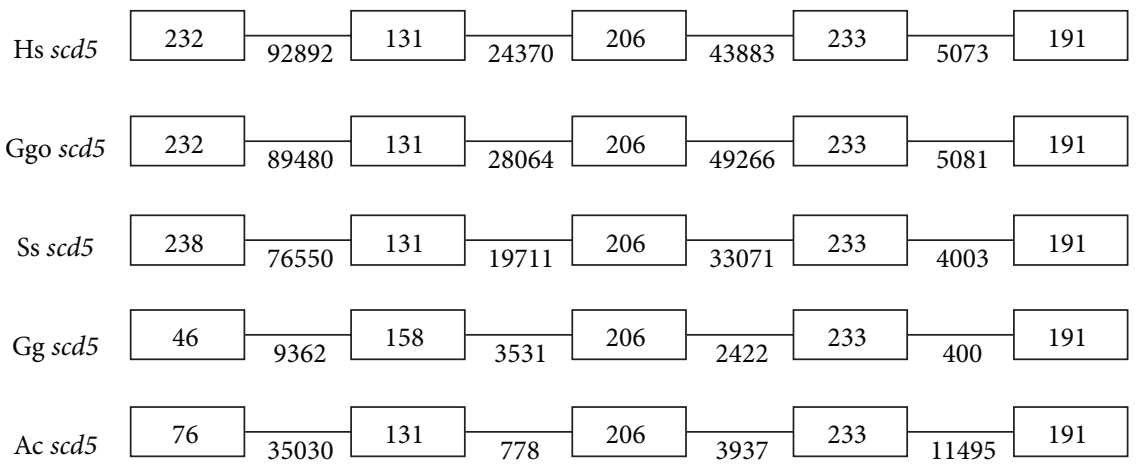

(b)

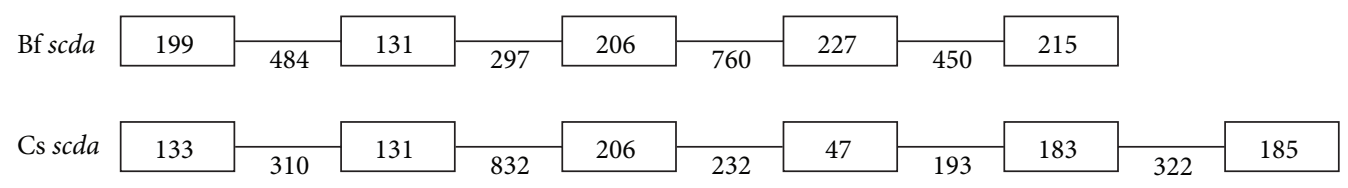

(c)

Figure 2: The exons size changes of $s c d$ genes. (a) Exon size changes of $s c d 1$ gene in vertebrates. (b) Exon size changes of $s c d 5$ gene in vertebrates. (c) Exon size changes of scd genes in invertebrates. Numbers in box represent the sizes of exons and numbers under bars represent the sizes of introns. Hs, Homo sapiens; Ggo, Gorilla gorilla; Ss, Sus scrofa; Md, Monodelphis domestica; Oa, Ornithorhynchus anatinus; Gg, Gallus gallus; Xt, Xenopus tropicalis; Dr, Danio rerio; Ac, Anolis carolinensis; Bf, Branchiostoma floridae; Cs, Ciona savignyi.

whereas the $s c d$ genes in vertebrates were diverged into two independently duplicated genes early in vertebrate evolution with strong support, in which all $s c d 1$ genes form a distinct clade and all scd5 genes clustered into another clade (Figures 3(a) and 3(b)). Our phylogenetic analysis was consistent with the previous studies by Castro et al. [6] and Lengi and Corl [11]. This pattern of duplication might be resulted from part of the two rounds of genome duplication in vertebrate ancestry [6].

When a gene duplication event occurs, the duplicated genes have redundant functions. The fate of the duplicated genes might be loss of function, gaining a new function, or subfunctionalization [51]. Subfunctionalization occurred when both duplicates can be stably maintained in the genome [52]. The division of gene expression after gene duplication appears to be a general form of subfunctionalization $[53,54]$. In this model, after gene duplication, complementary degenerate mutations are fixed randomly underrelaxed functional constraints [55]. Previous studies suggested that both $s c d 1$ and $s c d 5$ encode the same functional delta- 9 desaturase and are localized on endoplasmic reticulum (ER) membrane [3, 56]. However, the $s c d 1$ gene expressed ubiquitous, and $s c d 5$ 


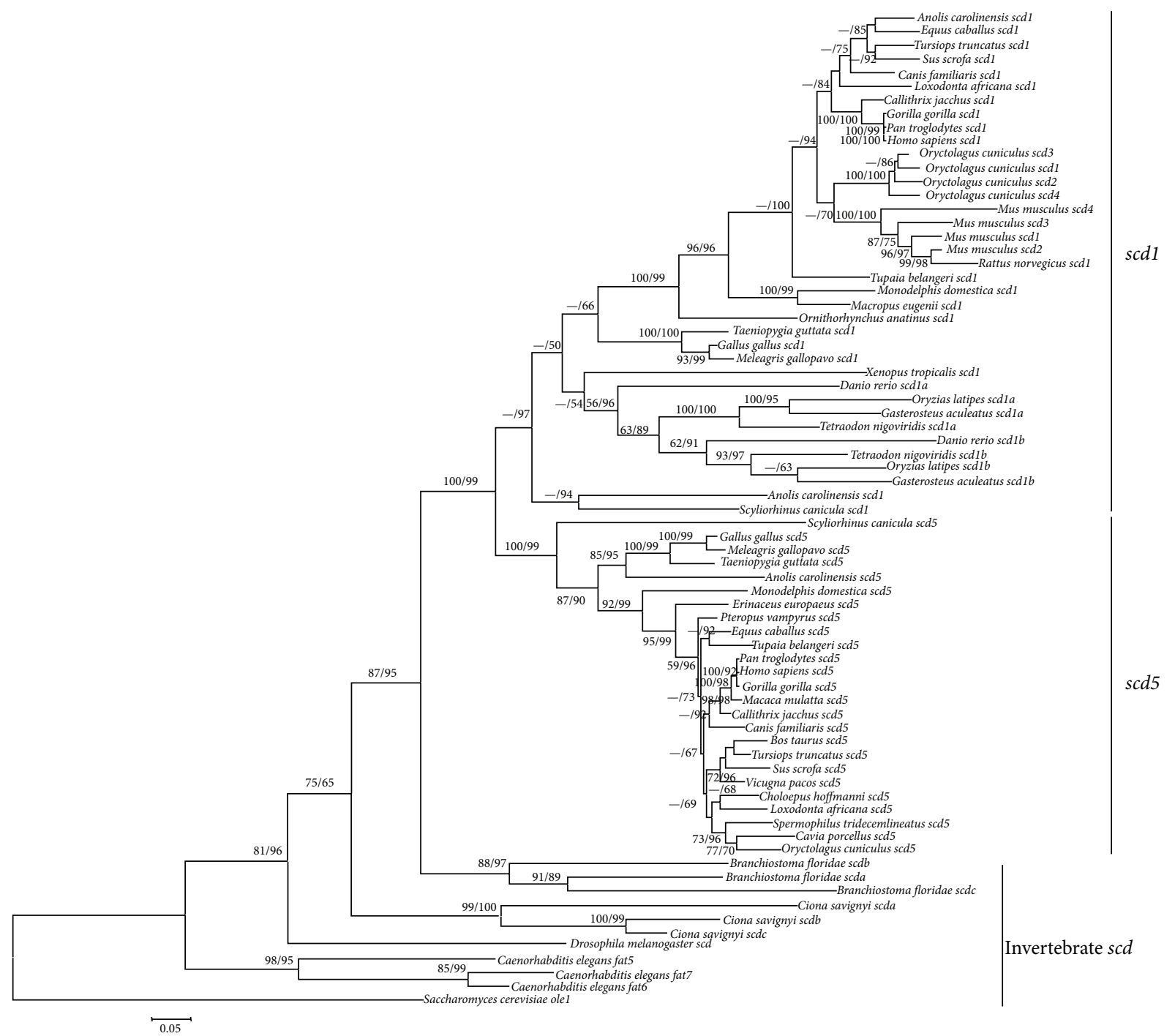

(a)

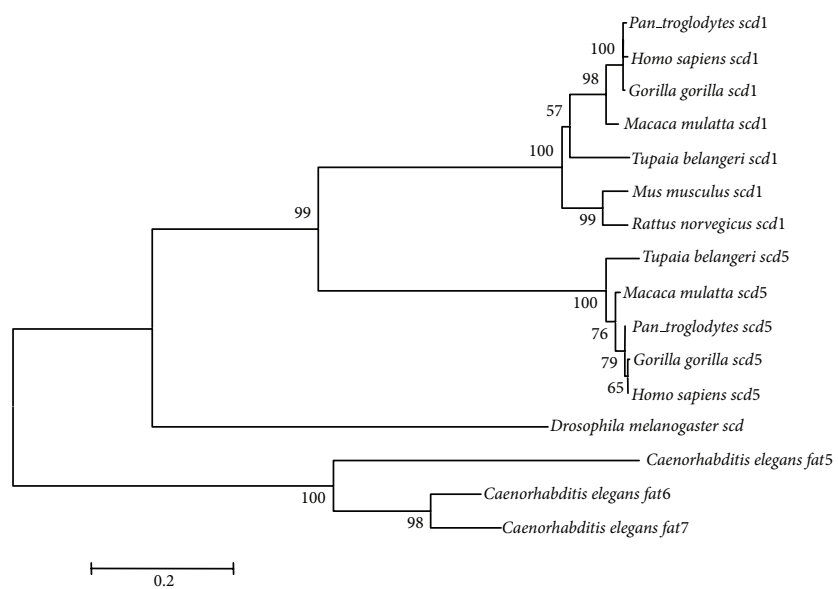

(b)

Figure 3: Phylogenetic trees of eukaryote scd isoforms. (a) Phylogenetic trees based on the nucleotide sequence data. The numbers on nodes indicated the support values, the former number was calculated using PHYML, and the latter number was calculated by FastTree 2.1.3. If bootstrap values were less than $50 \%$, they were defaulted. Trees were rooted by yeast ole1 gene. (b) Phylogenetic trees based on the amino acid sequences of 9 model animals with MEGA 4.0. The numbers on nodes indicated the support values. If bootstrap values were less than 50\%, they were defaulted. Trees were rooted by C. elegans SCD paralogs. 
TABLE 1: Selective patterns of scd genes estimated in CODEML.

\begin{tabular}{|c|c|c|c|c|}
\hline Model & $\ln L$ & Parameters estimates & $2 \Delta L$ & Positively selected sites \\
\hline \multicolumn{5}{|c|}{ Branch-specific models } \\
\hline M0 & -20340.727636 & $\omega=0.08684$ & & \\
\hline \multicolumn{5}{|l|}{ Model B } \\
\hline Scd1 two ratio & -20339.045042 & $\omega_{0}=0.09207, \omega_{1}=0.07951$ & 3.365188 & \\
\hline Scd5 two ratio & -20318.455800 & $\omega_{0}=0.06146, \omega_{1}=0.09735$ & $44.542672^{\# \# \#}$ & \\
\hline $\begin{array}{l}\text { Model C } \\
\text { Three ratio }\end{array}$ & -20315.506084 & $\begin{array}{c}\omega_{s c d 1}=0.06140 \\
\omega_{s c d 5}=0.09198 \\
\omega_{\text {invertebrate } s c d}=0.11788\end{array}$ & $50.443104^{\# \# \#}$ & \\
\hline \multicolumn{5}{|c|}{ Branch-site models } \\
\hline \multicolumn{5}{|l|}{ Scd1 } \\
\hline Model A1 & -20079.883939 & $\begin{array}{l}\omega_{0}=0.06891, \omega_{1}=1, \omega_{2}=1 \\
P_{0}=0.85305, P_{1}=0.04177\end{array}$ & & \\
\hline M1a & -20178.290653 & $\begin{array}{c}\omega_{0}=0.07950, \omega_{1}=1 \\
P_{0}=0.91928, P_{1}=0.08072\end{array}$ & $196.813428^{\# \# \#}$ & \\
\hline Model A & -20079.883939 & $\begin{array}{c}\omega_{0}=0.06891, \omega_{1}=1, \omega_{2}=1 \\
P_{0}=0.85305, P_{1}=0.04177\end{array}$ & 0 & $\begin{array}{c}108 \mathrm{~L}^{* *}, 109 \mathrm{~F}^{* *}, 201 \mathrm{~A}^{* *}, 206 \mathrm{~S}, 212 \mathrm{~K}^{* *} \\
247 \mathrm{Y}^{* *}, 254 \mathrm{~A}, 255 \mathrm{I}^{*}, 276 \mathrm{~K}^{* *}, 289 \mathrm{~V}^{*} \\
\text { 315P, 330Y, 339A }\end{array}$ \\
\hline \multicolumn{5}{|l|}{ Scd5 } \\
\hline Model A1 & -20129.099054 & $\begin{array}{c}\omega_{0}=0.07500, \omega_{1}=1, \omega_{2}=1 \\
P_{0}=0.88996, P_{1}=0.05968\end{array}$ & & \\
\hline Mla & -20168.513281 & $\begin{array}{c}\omega_{0}=0.07951, \omega_{1}=1 \\
P_{0}=0.91900, P_{1}=0.08100\end{array}$ & $78.828454^{\# \# \#}$ & \\
\hline Model A & -20129.099054 & $\begin{array}{c}\omega_{0}=0.07500, \omega_{1}=1, \omega_{2}=1 \\
P_{0}=0.88996, P_{1}=0.05968\end{array}$ & 0 & $\begin{array}{c}157 \mathrm{~A}^{* *}, 194 \mathrm{P}^{* *}, 215 \mathrm{M}^{* *}, 223 \mathrm{P}, 230 \mathrm{I} \\
338 \mathrm{~A}^{* *}\end{array}$ \\
\hline
\end{tabular}

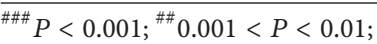

${ }^{* *} P>0.99 ;{ }^{*} P>0.95$.

TABLE 2: Transcription factor binding sites predicted at the $5{ }^{\prime} U T R$ of $h s c d 5$.

\begin{tabular}{lccc}
\hline Transcription factor & Binding sites & Position $(h s c d 1)^{\$}$ & Position $(h s c d 5)$ \\
\hline C/EBP $\alpha$ & GMAAA & -219 & $-1061,-1648$ \\
AP1 & TGACC & $-204,-271$ & $-580,-643$ \\
SP1 & GGCGG & $-304,-314,-551$ & $-286,-946$ \\
NF-Y & CCAAT & $-458,-501$ & $-397,-976$ \\
NF-1 & TTGGC & $-459,-502$ & -395 \\
SREBP1 & TCACC & -517 & $-892^{*}$ \\
PPAR $\alpha$ & AAAG/GGTCA & -1186 & $-579^{\#}$ \\
T3R & GGTCA & -2228 & $-1223,-2245$ \\
\hline
\end{tabular}

T3R: tri-iodothyronine receptor; AP1: activator protein 1; NF-1/Y: nuclear factor 1/Y; SREBP1: sterol regulatory element binding protein; PPAR $\alpha$ : peroxisome proliferator-activated receptor; $\mathrm{C} / \mathrm{EBP} \alpha$ : $\mathrm{CAAT} /$ enhancer binding protein.

\$These transcription factor binding sites were from [64].

\# Predicted by PROMO.

* Only found in human using TRANSFAC.

gene expressed mainly in brain in different species $[3,6$, 11]. We inferred that the evolution of $s c d$ genes might be a division of gene expression subsequent to gene duplication. This pattern was supported by the evolutionary forces behind the expression division of duplicate genes. The relative rate test suggested that the two duplicated scd genes evolved at the similar rate. The selective constraints analysis suggested that the $s c d 1$ and $s c d 5$ were both under strict purifying selection
(Table 1), which was consistent with the conserved delta-9 desaturase of both $s c d$ genes. Intriguingly, in the branch-site analysis, we detected that some sites within $s c d 1$ and $s c d 5$ were underrelaxed selective pressure. These sites might be resulted from the random fixation of the complementary degenerate mutations that were underrelaxed functional constraints.

Though both of $s c d 1$ and $s c d 5$ encoded delta-9 desaturase, producing a palmitoleic acid (16:1n7) and oleic acid (18:1n9) 
(k)

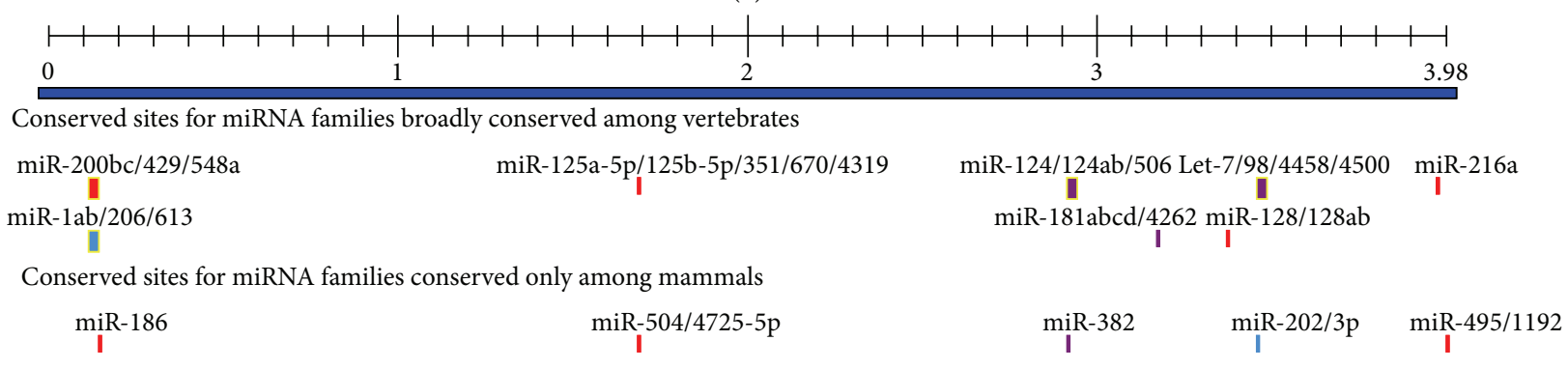

(a)

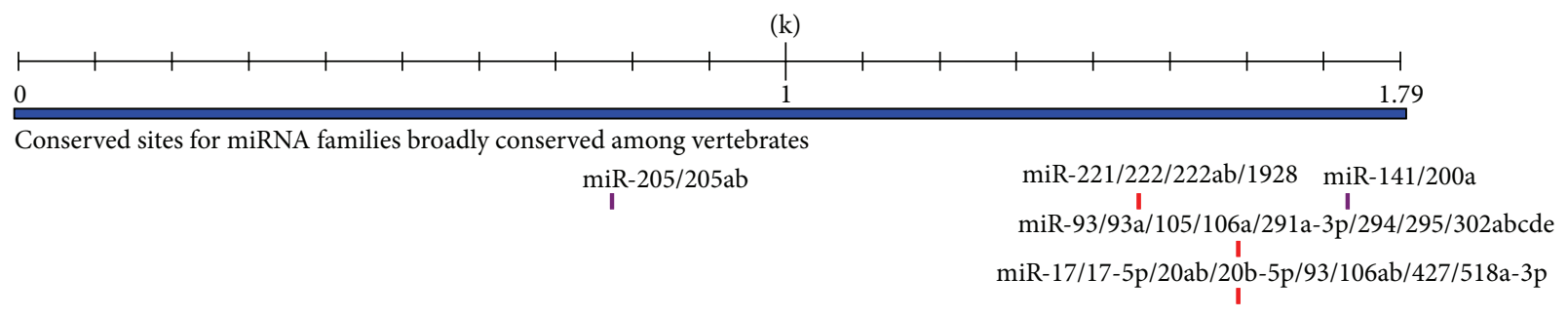

Conserved sites for miRNA families conserved only among mammals

$$
\begin{gathered}
\text { miR-411 } \\
\text { I } \\
\text { miR-494 }
\end{gathered}
$$

Sites with higher probability of preferential conservation

Sites with lower probability of preferential conservation

- $8 \mathrm{mer}$

7mer-m8

$8 \mathrm{mer}$

$7 \mathrm{mer}-\mathrm{m} 8$

$7 \mathrm{mer}-1 \mathrm{~A}$

$7 \mathrm{mer}-1 \mathrm{~A}$

(b)

FIGURE 4: The target sites for miRNA families conserved among mammals and vertebrates at the $3^{\prime}$-UTR region of human $s c d 1$ gene (a) and $s c d 5$ gene (b). The sites with different probability of preferential conservation were marked in different colors. The target sites sharing among miRNAs separated by slash were marked with same color.

$[3,56]$, they expressed diversely in the physiological process. Previous studies had proposed that $s c d 1$ were associated with a variety of diseases including cancers, type 2 diabetes, and cardiovascular disorders [13], whereas $s c d 5$ might act a potential role for maintaining the optimum levels of oleic acid in brain development and physiological activities $[3,57]$. Castro et al. proposed that the major distinction between $s c d 5$ and $s c d 1$ would be at the regulatory level, in which $s c d 1$ gene expression was mainly modulated at the transcriptional level by a wide variety of hormones and nutrients, whereas $s c d 5$ was not responsive to external inputs like food sources [6]. In this study, we predicted the transcription factor binding sites at the $5^{\prime}$-UTR region and the miRNA target sites at the $3^{\prime}$-UTR region of human $s c d 5$ gene. The transcription factor binding sites detected in $s c d 1$ gene [13] could also be detected in scd5 gene. However, the SREBP1 binding site only presents in human $s c d 5$ gene, but not in other mammals, for example, rhesus monkey, pig and others. This might be that the prediction of transcription factor (TF) binding sites was based on known TF binding sites so that some new TF binding sites can not be detected. Recent studies have suggested that SREBP1 regulates the expression of $s c d 5$ in primary cultures of human skeletal muscle cells [58], or directly binding to the promoter region of $s c d 5$ in bovine [59].
In contrast, a study on human hepatocyte cell line suggested that SREBP1 only binds to the $s c d 1$ gene, but not to $s c d 5$ gene [31]. This discrepancy might be the distinct expression of $s c d 5$ gene in different species or tissues. From our prediction, we conclude that the TF binding sites predicted in $s c d 5$ gene were very similar to these of $s c d 1$ gene, suggesting that the regulators may also be similar between two $s c d$ genes. Certainly, these TF predictions need further experimental verification.

miRNAs regulation is another gene regulatory mechanism in posttranscriptional regulation. Gu et al. estimated the time of vertebrate miRNA duplication events and suggested that gene/genome duplications in the early stage of vertebrates may expand the protein-encoding genes and miRNAs simultaneously [60]. Gene duplication events, followed by subfunctionalization and neofunctionalization processes, are considered to be a major source for emergence of novel miRNA genes [61]. In this study, the lengths of $3^{\prime}$-UTR of $s c d 1$ and $s c d 5$ gene are about $4000 \mathrm{bp}$ and $1790 \mathrm{bp}$, respectively (Figure 4). A previous study suggested that genes with longer $3^{\prime}$-UTRs are regulated by more distinct types of miRNAs [62]. In our analysis, 13 miRNAs targeting sites are detected in the $3^{\prime}$-UTR of $s c d 1$ gene, while 7 miRNAs targeting sites are detected in the $3^{\prime}$-UTR of $s c d 5$ gene. Additionally, the length 
changes of $3^{\prime}$-UTRs in these two $s c d$ genes might suggest a differentiation of the regulatory mechanisms. miRNAs predicted to target the $3^{\prime}$-UTR region of $s c d 1$ gene are associated with breast cancers, hepatocellular carcinoma, and metabolic syndromes such as diabetes, NAFLD. However, most of the miRNAs predicted to target the $3^{\prime}$-UTR region of $s c d 5$ gene are related to the neurogenic disease and pancreatic cancer; and only 2 microRNAs are associated with the NAFLD. This regulatory pattern might be due to the high expression of $s c d 5$ gene in brain and pancreas [3]. Additionally, a recent study has reported that the $s c d 5$ gene plays a key role in the regulation of the neuronal cell proliferation and differentiation [56]. These results might indicate that the expression of $s c d 5$ is implicated in brain development and physiological activity.

In addition, we also investigated the size and order of exons of $s c d$ genes. We found that the $s c d 1$ gene has an extra exon (exon1) compared to scd5 gene (Figure 2). The first 45 amino acids of SCD1 were highly different from those of SCD5 (Figure 1). Though there is no histidine domain and transmembrane domain exists in this part of SCD1, about 30 residues constitute a motif responsible for the rapid degradation of SCD [63]. This result indicated that the degradation of two SCD might be very different. However, due to no information on the degradation of SCD5, the evolutionary changes of regulation on both $s c d$ genes and SCD proteins still need further investigation.

\section{Conclusion}

In summary, this study of evolutionary pattern of $s c d$ genes showed that $s c d 1$ and $s c d 5$ genes emerged due to the duplication event as well as that they may play different roles. We also detected that the scd genes were evolved at the similar rate and were under strictly purifying selection, consistent with the conserved function of delta-9 desaturase of both SCD. Furthermore, our study revealed several potentially adaptive amino acid changes, which might be resulted from the random fixation of the complementary degenerate mutations underrelaxed functional constraints. The prediction of transcriptional factor binding sites at the $5^{\prime}$-UTR and miRNAs at $3^{\prime}$-UTR of $s c d$ genes suggested that the regulators of $s c d 5$ may be different from $s c d 1$ gene, supportting the differentiation at the regulatory levels between $s c d 5$ and $s c d 1$. These findings increase the current knowledge of evolutionary patterns and function of scd genes in eukaryote. Yet, further experimental investigations need to elucidate the regulation and function of $s c d$ genes, especially the $s c d 5$ gene.

\section{Conflict of Interests}

All authors declared no conflict of interests.

\section{Authors' Contribution}

Xiaoyun $\mathrm{Wu}$ and Xiaoju Zou contributed equally to this paper.

\section{Acknowledgments}

The authors thank the anonymous referees for their constructive and helpful comments and suggestions. This work was supported by the Innovative Program of the Chinese Academy of Sciences (KSCX2-EW-R-12 and KSCX2-EWJ-23) to Bin Liang, the National 863 Project of China (2012AA021801 and 2012AA022402), the National Natural Science Foundation of China (Y301261041, U1202223, 31160216, and 31171134), and the West Light Foundation to Xiaoyun Wu from the Chinese Academy of Sciences, and State Key Laboratory of Genetic Resources and Evolution, Kunming Institute of Zoology, Chinese Academy of Sciences (GREKF13-03).

\section{References}

[1] F. S. Heinemann and J. Ozols, "Stearoyl-CoA desaturase, a short-lived protein of endoplasmic reticulum with multiple control mechanisms," Prostaglandins Leukotrienes and Essential Fatty Acids, vol. 68, no. 2, pp. 123-133, 2003.

[2] P. Strittmatter, L. Spatz, and D. Corcoran, "Purification and properties of rat liver microsomal stearyl coenzyme A desaturase," Proceedings of the National Academy of Sciences of the United States of America, vol. 71, no. 11, pp. 4565-4569, 1974.

[3] J. Wang, L. Yu, R. E. Schmidt et al., "Characterization of HSCD5, a novel human stearoyl-CoA desaturase unique to primates," Biochemical and Biophysical Research Communications, vol. 332, no. 3, pp. 735-742, 2005.

[4] C. M. Paton and J. M. Ntambi, "Biochemical and physiological function of stearoyl-CoA desaturase," American Journal of Physiology-Endocrinology and Metabolism, vol. 297, no. 1, pp. E28-E37, 2009.

[5] M. T. Flowers and J. M. Ntambi, "Role of stearoyl-coenzyme A desaturase in regulating lipid metabolism," Current Opinion in Lipidology, vol. 19, no. 3, pp. 248-256, 2008.

[6] L. F. C. Castro, J. M. Wilson, O. Gonçalves, S. GalanteOliveira, E. Rocha, and I. Cunha, "The evolutionary history of the stearoyl-CoA desaturase gene family in vertebrates," $B M C$ Evolutionary Biology, vol. 11, no. 1, article 132, 2011.

[7] J. L. Watts and J. Browse, "A palmitoyl-CoA-specific $\Delta 9$ fatty acid desaturase from Caenorhabditis elegans," Biochemical and Biophysical Research Communications, vol. 272, no. 1, pp. 263269, 2000.

[8] T. J. Brock, J. Browse, and J. L. Watts, "Genetic regulation of unsaturated fatty acid composition in C. elegans," PLoS Genetics, vol. 2, no. 7, article e108, 2006.

[9] T. J. Brock, J. Browse, and J. L. Watts, "Fatty acid desaturation and the regulation of adiposity in Caenorhabditis elegans," Genetics, vol. 176, no. 2, pp. 865-875, 2007.

[10] J. E. Stukey, V. M. McDonough, and C. E. Martin, "Isolation and characterization of OLE1, a gene affecting fatty acid desaturation from Saccharomyces cerevisiae," The Journal of Biological Chemistry, vol. 264, no. 28, pp. 16537-16544, 1989.

[11] A. J. Lengi and B. A. Corl, "Comparison of pig, sheep and chicken SCD5 homologs: evidence for an early gene duplication event," Comparative Biochemistry and Physiology B, vol. 150, no. 4, pp. 440-446, 2008. 
[12] H. Evans, T. De Tomaso, M. Quail et al., "Ancient and modern duplication events and the evolution of stearoyl-CoA desaturases in teleost fishes," Physiological Genomics, vol. 35, no. 1, pp. 18-29, 2008.

[13] D. Mauvoisin and C. Mounier, "Hormonal and nutritional regulation of SCD1 gene expression," Biochimie, vol. 93, no. 1, pp. 78-86, 2011.

[14] T. A. Hall, "Bioedit: a user-friendly biological sequence alignment editor and analysis program for windows 95/98/Nt," Nucleic Acids Symposium Series, vol. 41, pp. 95-98, 1999.

[15] S. Guindon and O. Gascuel, "A simple, fast, and accurate algorithm to estimate large phylogenies by maximum likelihood," Systematic Biology, vol. 52, no. 5, pp. 696-704, 2003.

[16] M. N. Price, P. S. Dehal, and A. P. Arkin, "FastTree 2approximately maximum-likelihood trees for large alignments," PLoS ONE, vol. 5, no. 3, Article ID e9490, 2010.

[17] J. Felsenstein, "Confidence limits on phylogenies: an approach using bootstrap," Evolution, vol. 39, pp. 783-791, 1985.

[18] S. Guindon, F. Delsuc, J.-F. Dufayard, and O. Gascuel, "Estimating maximum likelihood phylogenies with PhyML," Methods in Molecular Biology, vol. 537, pp. 113-137, 2009.

[19] S. Guindon, J.-F. Dufayard, V. Lefort, M. Anisimova, W. Hordijk, and O. Gascuel, "New algorithms and methods to estimate maximum-likelihood phylogenies: assessing the performance of PhyML 3.0," Systematic Biology, vol. 59, no. 3, pp. 307-321, 2010.

[20] K. Tamura, J. Dudley, M. Nei, and S. Kumar, "MEGA4: molecular evolutionary genetics analysis (MEGA) software version 4.0," Molecular Biology and Evolution, vol. 24, no. 8, pp. 15961599, 2007.

[21] X. Messeguer, R. Escudero, D. Farré, O. Núñez, J. Martínez, and M. M. Albà, "PROMO: detection of known transcription regulatory elements using species-tailored searches," Bioinformatics, vol. 18, no. 2, pp. 333-334, 2002.

[22] D. Farré, R. Roset, M. Huerta et al., "Identification of patterns in biological sequences at the ALGGEN server: PROMO and MALGEN," Nucleic Acids Research, vol. 31, no. 13, pp. 3651-3653, 2003.

[23] M. Robinson-Rechavi and D. Huchon, "RRTree: relative-rate tests between groups of sequences on a phylogenetic tree," Bioinformatics, vol. 16, no. 3, pp. 296-297, 2000.

[24] Z. Yang and R. Nielsen, "Estimating synonymous and nonsynonymous substitution rates under realistic evolutionary models," Molecular Biology and Evolution, vol. 17, no. 1, pp. 3243, 2000.

[25] Z. Yang, "PAML 4: phylogenetic analysis by maximum likelihood," Molecular Biology and Evolution, vol. 24, no. 8, pp. 15861591, 2007.

[26] Z. Yang, "Inference of selection from multiple species alignments," Current Opinion in Genetics and Development, vol. 12, no. 6, pp. 688-694, 2002.

[27] J. Zhang, R. Nielsen, and Z. Yang, "Evaluation of an improved branch-site likelihood method for detecting positive selection at the molecular level," Molecular Biology and Evolution, vol. 22, no. 12, pp. 2472-2479, 2005.

[28] H. B. Sanchez, L. Yieh, and T. F. Osborne, "Cooperation by sterol regulatory element-binding protein and Sp1 in sterol regulation of low density lipoprotein receptor gene," The Journal of Biological Chemistry, vol. 270, no. 3, pp. 1161-1169, 1995.

[29] S. M. Jackson, J. Ericsson, R. Mantovani, and P. A. Edwards, "Synergistic activation of transcription by nuclear factor Y and sterol regulatory element binding protein," Journal of Lipid Research, vol. 39, no. 4, pp. 767-776, 1998.

[30] K. A. Dooley, S. Millinder, and T. F. Osborne, "Sterol regulation of 3-hydroxy-3-methylglutaryl-coenzyme A synthase gene through a direct interaction between sterol regulatory element binding protein and the trimeric CCAAT-binding factor/nuclear factor Y," The Journal of Biological Chemistry, vol. 273, no. 3, pp. 1349-1356, 1998.

[31] B. D. Reed, A. E. Charos, A. M. Szekely, S. M. Weissman, and M. Snyder, "Genome-wide occupancy of SREBP1 and its partners NFY and SP1 reveals novel functional roles and combinatorial regulation of distinct classes of genes," PLoS Genetics, vol. 4, no. 7, Article ID e1000133, 2008.

[32] J. A. Foekens, A. M. Sieuwerts, M. Smid et al., "Four miRNAs associated with aggressiveness of lymph node-negative, estrogen receptor-positive human breast cancer," Proceedings of the National Academy of Sciences of the United States of America, vol. 105, no. 35, pp. 13021-13026, 2008.

[33] M. V. Iorio, M. Ferracin, C.-G. Liu et al., "MicroRNA gene expression deregulation in human breast cancer," Cancer Research, vol. 65, no. 16, pp. 7065-7070, 2005.

[34] N. Kondo, T. Toyama, H. Sugiura, Y. Fujii, and H. Yamashita, "MiR-206 expression is down-regulated in estrogen receptor $\alpha$ positive human breast cancer," Cancer Research, vol. 68, no. 13, pp. 5004-5008, 2008.

[35] A. Lujambio, S. Ropero, E. Ballestar et al., "Genetic unmasking of an epigenetically silenced microRNA in human cancer cells," Cancer Research, vol. 67, no. 4, pp. 1424-1429, 2007.

[36] X.-H. Huang, Q. Wang, J.-S. Chen et al., "Bead-based microarray analysis of microRNA expression in hepatocellular carcinoma: MiR-338 is downregulated," Hepatology Research, vol. 39, no. 8, pp. 786-794, 2009.

[37] L. Gramantieri, M. Ferracin, F. Fornari et al., "Cyclin G1 is a target of miR-122a, a MicroRNA frequently down-regulated in human hepatocellular carcinoma," Cancer Research, vol. 67, no. 13, pp. 6092-6099, 2007.

[38] Y. Zhao, H.-L. Jia, H.-J. Zhou et al., "Identification of metastasisrelated microRNAs of hepatocellular carcinoma in hepatocellular carcinoma cell lines by quantitative real time PCR," Chinese Journal of Hepatology, vol. 17, no. 7, pp. 526-530, 2009.

[39] S. Volinia, G. A. Calin, C. G. Liu et al., "A microRNA expression signature of human solid tumors defines cancer gene targets," Proceedings of the National Academy of Sciences of the United States of America, vol. 103, no. 7, pp. 2257-2261, 2006.

[40] J. L. Eun, Y. Gusev, J. Jiang et al., "Expression profiling identifies microRNA signature in pancreatic cancer," International Journal of Cancer, vol. 120, no. 5, pp. 1046-1054, 2007.

[41] L. Zheng, G.-C. Lv, J. Sheng, and Y.-D. Yang, "Effect of miRNA$10 \mathrm{~b}$ in regulating cellular steatosis level by targeting PPAR- $\alpha$ expression, a novel mechanism for the pathogenesis of NAFLD," Journal of Gastroenterology and Hepatology, vol. 25, no. 1, pp. 156-163, 2010.

[42] A. Alisi, L. Da Sacco, G. Bruscalupi et al., "Mirnome analysis reveals novel molecular determinants in the pathogenesis of diet-induced nonalcoholic fatty liver disease," Laboratory Investigation, vol. 91, no. 2, pp. 283-293, 2011.

[43] N. Klöting, S. Berthold, P. Kovacs et al., "MicroRNA expression in human omental and subcutaneous adipose tissue," PLoS ONE, vol. 4, no. 3, Article ID e4699, 2009.

[44] M. Kato, S. Putta, M. Wang et al., “TGF- $\beta$ activates Akt kinase through a microRNA-dependent amplifying circuit targeting PTEN," Nature Cell Biology, vol. 11, no. 7, pp. 881-889, 2009. 
[45] K. Abu-Elneel, T. Liu, F. S. Gazzaniga et al., "Heterogeneous dysregulation of microRNAs across the autism spectrum," Neurogenetics, vol. 9, no. 3, pp. 153-161, 2008.

[46] B. Malzkorn, M. Wolter, F. Liesenberg et al., "Identification and functional characterization of microRNAs involved in the malignant progression of gliomas," Brain Pathology, vol. 20, no. 3, pp. 539-550, 2010.

[47] D. O. Perkins, C. D. Jeffries, L. F. Jarskog et al., "MicroRNA expression in the prefrontal cortex of individuals with schizophrenia and schizoaffective disorder," Genome Biology, vol. 8, no. 2, article R27, 2007.

[48] M. Bloomston, W. L. Frankel, F. Petrocca et al., "MicroRNA expression patterns to differentiate pancreatic adenocarcinoma from normal pancreas and chronic pancreatitis," The Journal of the American Medical Association, vol. 297, no. 17, pp. 1901-1908, 2007.

[49] J.-K. Park, E. J. Lee, C. Esau, and T. D. Schmittgen, "Antisense inhibition of microRNA-21 or -221 arrests cell cycle, induces apoptosis, and sensitizes the effects of gemcitabine in pancreatic adenocarcinoma," Pancreas, vol. 38, no. 7, pp. e190-e199, 2009.

[50] T. Greither, L. F. Grochola, A. Udelnow, C. Lautenschläger, P. Würl, and H. Taubert, "Elevated expression of microRNAs 155, 203, 210 and 222 in pancreatic tumors is associated with poorer survival," International Journal of Cancer, vol. 126, no. 1, pp. 7380, 2010.

[51] J. Z. Zhang, "Evolution by gene duplication: an update," Trends in Ecology and Evolution, vol. 18, no. 6, pp. 292-298, 2003.

[52] M. A. Nowak, M. C. Boerlijst, J. Cooke, and J. M. Smith, "Evolution of genetic redundancy," Nature, vol. 388, no. 6638, pp. 167-171, 1997.

[53] A. Wagner, "Decoupled evolution of coding region and mRNA expression patterns after gene duplication: implications for the neutralist-selectionist debate," Proceedings of the National Academy of Sciences of the United States of America, vol. 97, no. 12, pp. 6579-6584, 2000.

[54] Z. Gu, D. Nicolae, H. H.-S. Lu, and W.-H. Li, "Rapid divergence in expression between duplicate genes inferred from microarray data," Trends in Genetics, vol. 18, no. 12, pp. 609-613, 2002.

[55] A. Force, M. Lynch, F. B. Pickett, A. Amores, Y.-L. Yan, and J. Postlethwait, "Preservation of duplicate genes by complementary, degenerative mutations," Genetics, vol. 151, no. 4, pp. 1531$1545,1999$.

[56] D. I. Sinner, G. J. Kim, G. C. Henderson, and R. A. Igal, "StearoylCoA desaturase-5: a novel regulator of neuronal cell proliferation and differentiation," PLoS One, vol. 7, no. 6, Article ID e39787, 2012.

[57] A. J. Lengi and B. A. Corl, "Identification and characterization of a novel bovine stearoyl-CoA desaturase isoform with homology to human SCD5," Lipids, vol. 42, no. 6, pp. 499-508, 2007.

[58] S. Rome, V. Lecomte, E. Meugnier et al., "Microarray analyses of SREBP-1a and SREBP-1c target genes identify new regulatory pathways in muscle," Physiological Genomics, vol. 34, no. 3, pp. 327-337, 2008.

[59] A. J. Lengi and B. A. Corl, "Regulation of the bovine SCD5 promoter by EGR2 and SREBP1," Biochemical and Biophysical Research Communications, vol. 421, no. 2, pp. 375-379, 2012.

[60] X. Gu, Z. Su, and Y. Huang, "Simultaneous expansions of micrornas and protein-coding genes by gene/genome duplications in early vertebrates," Journal of Experimental Zoology B, vol. 312, no. 3, pp. 164-170, 2009.
[61] E. Berezikov, "Evolution of microRNA diversity and regulation in animals," Nature Reviews Genetics, vol. 12, no. 12, pp. 846860, 2011.

[62] C. Cheng, N. Bhardwaj, and M. Gerstein, "The relationship between the evolution of microRNA targets and the length of their UTRs," BMC Genomics, vol. 10, article 431, 2009.

[63] H. Mziaut, G. Korza, and J. Ozols, "The N terminus of microsomal $\Delta 9$ stearoyl-CoA desaturase contains the sequence determinant for its rapid degradation," Proceedings of the National Academy of Sciences of the United States of America, vol. 97, no. 16, pp. 8883-8888, 2000.

[64] L. Zhang, L. Ge, T. Tran, K. Stenn, and S. M. Prouty, "Isolation and characterization of the human stearoyl-CoA desaturase gene promoter: requirement of a conserved CCAAT ciselement," Biochemical Journal, vol. 357, part 1, pp. 183-193, 2001. 

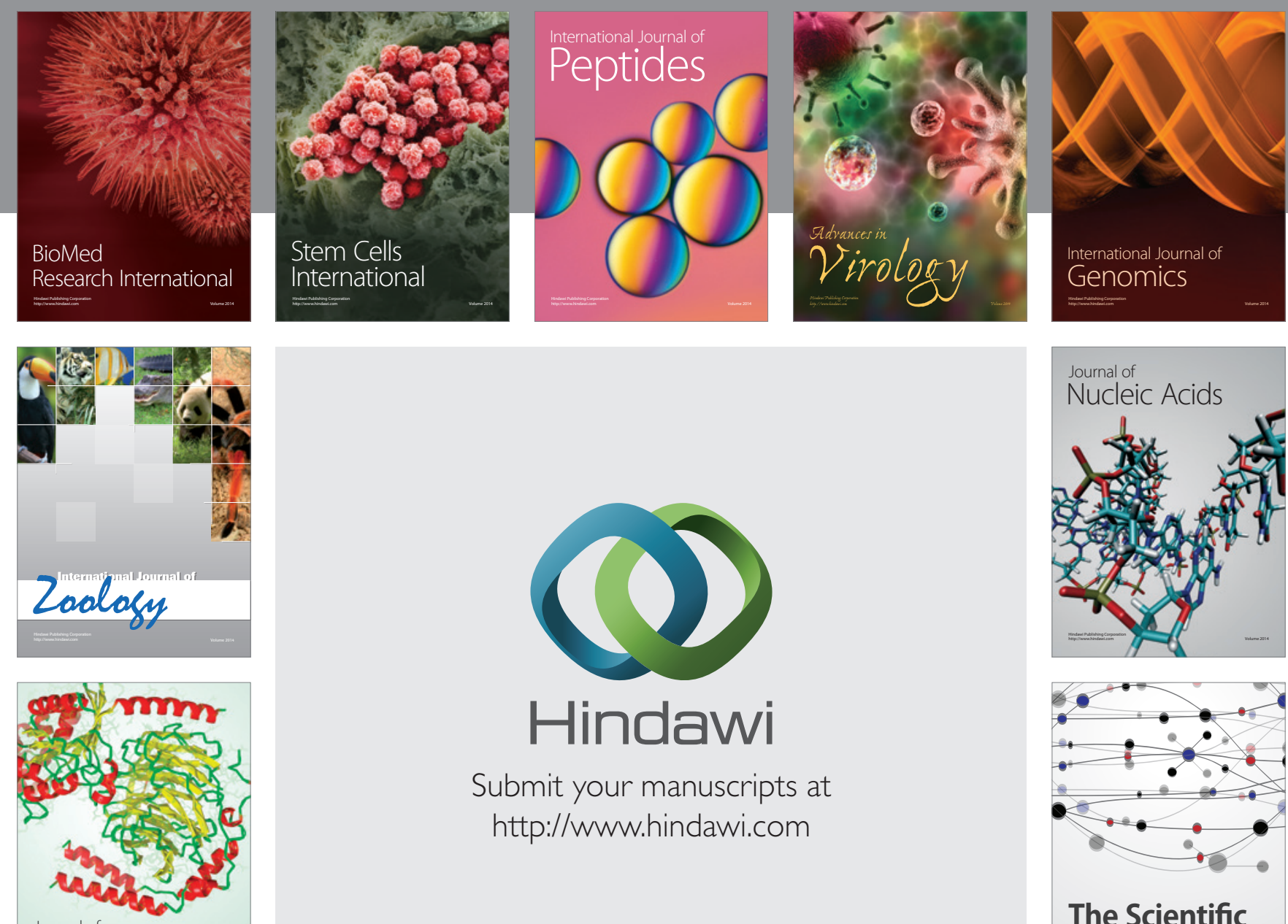

Submit your manuscripts at

http://www.hindawi.com

Journal of
Signal Transduction
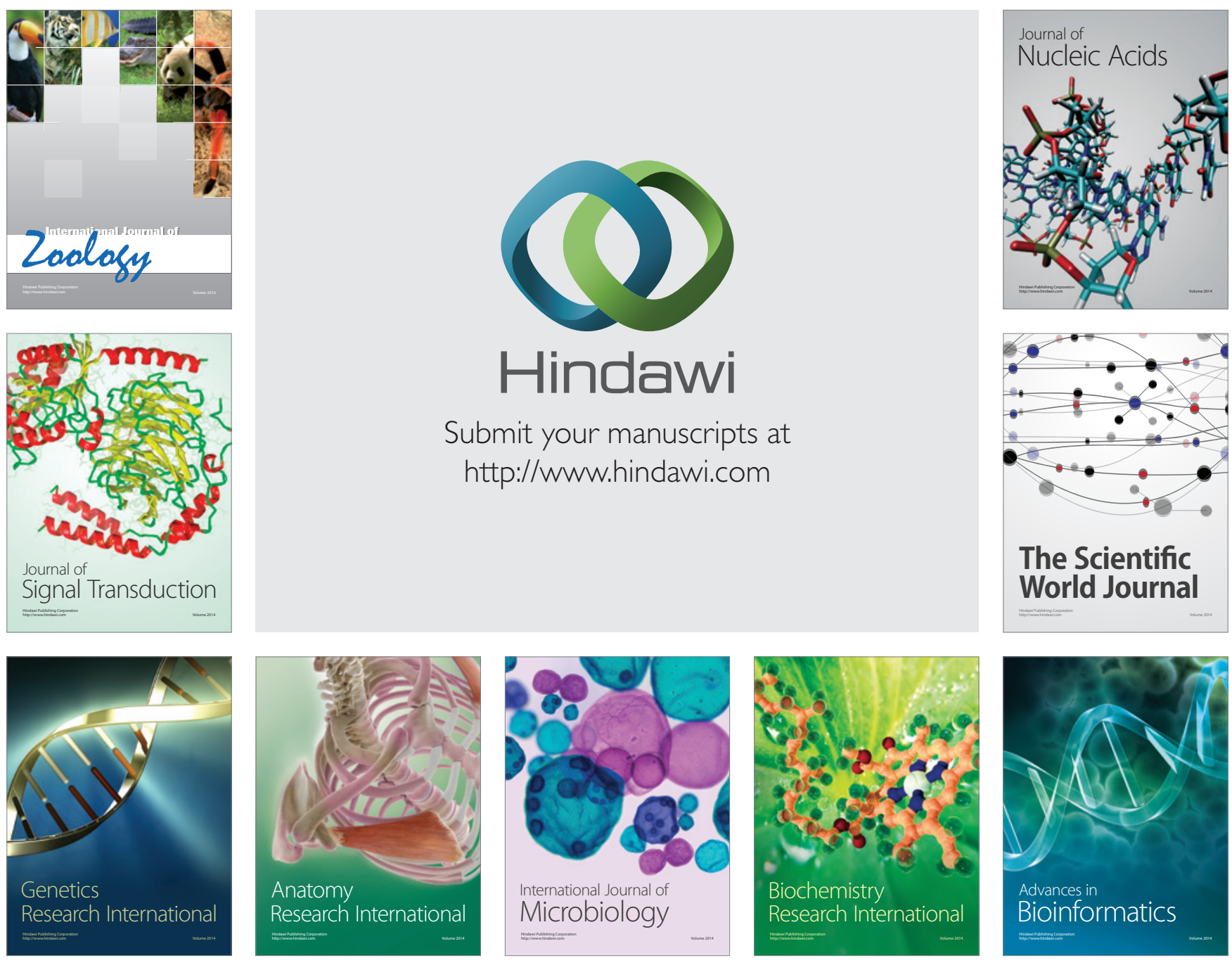

The Scientific World Journal
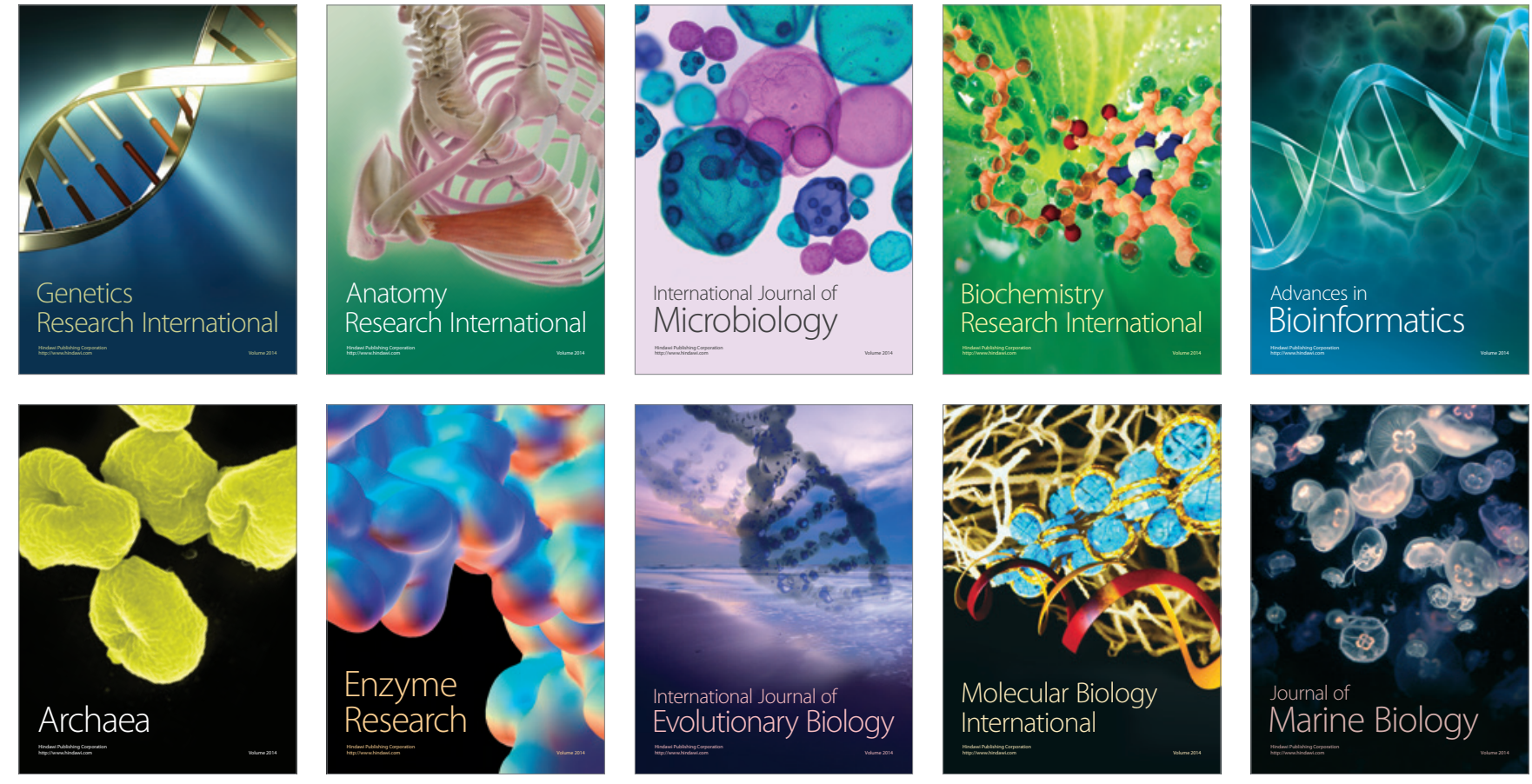